\title{
Schlechtere Prognose für normalgewichtige Typ-2-Diabetiker
}

Fragestellung: Haben Typ-2-Diabetiker, die zu Beginn der Erkrankung normalgewichtig sind, eine bessere oder schlechtere Prognose als übergewichtige Typ-2-Diabetiker?

Hintergrund: Übergewicht ist ein anerkannter Risikofaktor für viele Erkrankungen mit verkürzter Lebenserwartung. Deshalb bezeichnet man als Adipositas-Paradoxon die Beobachtung, dass übergewichtige Patienten bei einigen Erkrankungen bessere Überlebens-Chancen haben. Derartige Befunde bei Diabetikern wurden allerdings kritisiert, weil zu Beginn der Studien die Diabetesdauer nicht ausreichend bekannt war und viele $\mathrm{Pa}$ tienten bereits kardiovaskuläre Erkrankungen hatten.

Patienten und Methodik: Deshalb wurden für die Auswertung dieser fünf Kohortenstudien nur Patienten mit neu entdecktem Diabetes aufgenommen, also diejenigen, die während der Verlaufsbeobachtung diabetisch wurden. Normalgewicht, Übergewicht und Adipositas waren als BMI von 18,5-24,9, 25-29,9 und $\geq 30 \mathrm{~kg} / \mathrm{m}^{2}$ definiert. 2625 Patienten jenseits des 40 . Lebensjahres konnten im Mittel über 10 Jahre beobachtet werden. 12\% der Typ-2-Diabetiker waren normalgewichtig.

Ergebnisse: Es wurden 449 Todesfälle registriert, davon 178 aus kardiovaskulärer, 253 aus

Carnethon MR, De Chavez PJD, Biggs ML et al. Association of weight status with mortality in adults with incident diabetes. JAMA 2012;308 (6):581-90. nicht kardiovaskulärer und 18 aus unbekannter Ursache. Bei der Analyse wurden neun Einflussfaktoren, darunter natürlich auch Blutdruck, Lipidstatus und Rauchgewohnheiten berücksichtigt. Bei normalge-
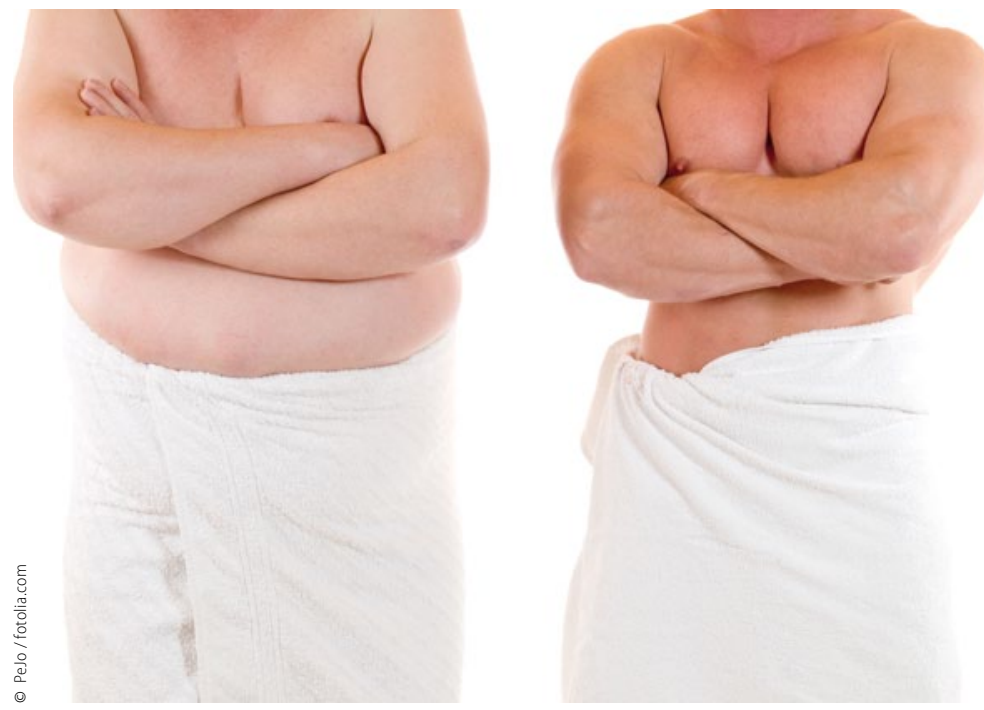

Dünn sein ist nicht immer besser, denn übergewichtige Typ-2-Diabetiker leben offenbar länger als normalgewichtige.

wichtigen Typ-2-Diabetikern waren die Gesamtmortalität um das 2,08-Fache, die nicht-kardiovaskuläre Mortalität um das 2,32-Fache (jeweils signifikant) und die kardiovaskuläre Mortalität um das 1,52-Fache (nicht signifikant) erhöht im Vergleich zu übergewichtigen und adipösen Patienten.

Schlussfolgerung: Typ-2-Diabetiker, die zu Beginn ihrer Stoffwechselerkrankung normalgewichtig sind, haben eine höhere Mortalität als übergewichtige und adipöse Typ-2-Diabetiker.

\section{- Kommentar von Prof. Dr. med. Heinrich Holzgreve}

\section{Erklären die Gene das Paradoxon?}

Zweifellos begünstigt Übergewicht schwerwiegende Erkrankungen wie Diabetes, Hypertonie, Herzinsuffizienz und Schlaganfall, die alle die Lebenserwartung verkürzen. Die vorliegenden Ergebnisse jedoch zeigen, dass Typ-2-Diabetiker mit Übergewicht am Beginn ihrer Erkrankung eine bessere Prognose haben als normalgewichtige Typ-2-Diabetiker. Diesen Vorteil von Übergewicht kennt man auch von Patienten mit Hypertonie, Herzinsuffizienz und schweren Nierenerkrankungen. Erklärungsversuche unterstellen gemeinhin Tabakrauchen, unerkannte Begleiterkrankungen oder andere Einflussfaktoren. Die Autoren verwerfen aufgrund ihrer Analysen und der Befunde aus der Literatur alle diese Ursachen und postulieren für normalgewichtige Diabetiker ein

besonderes genetisches Profil mit prognostisch ungünstiger Belastung.

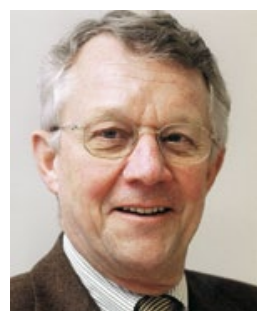

Prof. Dr. med. Heinrich Holzgreve

Internist, Kardiologische Praxis

Burgstr. 7, 80331 München

h.holzgreve@t-online.de 